\title{
Invasion Success of Bunias orientalis (Warty Cabbage) in Grasslands: A Mesocosm Experiment on the Role of Hydrological Stress and Disturbance
}

\author{
Anna Corli ${ }^{1}$, Julia Walter ${ }^{2+}$ and Christine S. Sheppard ${ }^{3 *+}$ \\ ${ }^{1}$ Department of Earth and Environmental Sciences, University of Pavia, Pavia, Italy, ${ }^{2}$ Landwirtschaftliches \\ Technologiezentrum Augustenberg, Pflanzenproduktion, Rheinstetten, Germany, ${ }^{3}$ Institute of Landscape and Plant Ecology, \\ University of Hohenheim, Stuttgart, Germany
}

\section{OPEN ACCESS}

Edited by:

Justin S. H. Wan

Jiangsu University, China

Reviewed by:

Dima Chen,

China Three Gorges University, China

Shaokun Wang,

Chinese Academy of Sciences (CAS),

China

*Correspondence:

Christine S. Sheppard

christine.sheppard@uni-

hohenheim.de

tThese authors have contributed equally to this work

Specialty section: This article was submitted to

Population and Evolutionary

Dynamics,

a section of the journal

Frontiers in Ecology and Evolution

Received: 03 November 2020 Accepted: 01 March 2021

Published: 18 March 2021

Citation:

Corli A, Walter $J$ and

Sheppard CS (2021) Invasion Success of Bunias orientalis Warty

Cabbage) in Grasslands:

A Mesocosm Experiment on the Role

of Hydrological Stress and Disturbance.

Front. Ecol. Evol. 9:625587. doi: 10.3389/fevo.2021.625587
Climate change is altering precipitation patterns, with higher frequency and magnitude of extreme events. Specifically, longer and more pronounced waterlogged conditions are predicted after rain spells as well as more frequent droughts, especially in Central Europe. Such hydrological changes can severely affect species performance and alter the function of ecosystems, as well as favor plant invasions. Competition with native communities may change depending on water stress. Bunias orientalis is an invasive plant that may benefit from disturbance or precipitation changes. We conducted a 3-year mesocosm experiment in a common garden to investigate how invasion success of $B$. orientalis in native German grassland communities is affected by varying hydrological conditions (from very dry to waterlogged). We measured the establishment and growth of $B$. orientalis in varying water table depths in bare soil (simulating disturbance) vs. in the community. Establishment and biomass of $B$. orientalis was generally highest under non-stress conditions. The species was also highly tolerant to dry conditions, but only when growing in bare soil. However, performance of $B$. orientalis was generally low, whereby interspecific competition in communities greatly limited invasion success. This might be due to the low competitive ability of the species in conditions of hydrological stress and the near-natural grassland communities with an extensive mowing regime used in our experiment. Our results suggest that invasion success of $B$. orientalis in grasslands will not increase if precipitation patterns change toward more extreme events. However, disturbance that creates bare soil patches might favor $B$. orientalis under drought conditions.

Keywords: Bunias orientalis, common garden experiment, grassland, hydrological gradient, interspecific competition, plant invasion, precipitation changes

\section{INTRODUCTION}

Climatic change leads to changes in precipitation patterns as well as higher frequency and magnitude of extreme events, which are projected to increase further during the 21st century for many areas (IPCC, 2014). Dry regions in mid latitudes and subtropics are expected to receive less annual precipitation whereas moist mid-latitudinal regions and higher latitudes receive more. 
However, many uncertainties regarding possible changes and impacts of annual precipitation in the future remain (Orlowsky and Seneviratne, 2013).

In regions that overall receive more precipitation such as Central Europe (IPCC, 2014), hydrological change is predicted to severely affect soil moisture, causing longer and more pronounced waterlogged conditions after extreme rain spells and flooding. Nevertheless, as already observed in Europe in the last decade (Hanel et al., 2018), changes in precipitation patterns might also result more frequently in dry conditions, causing hot and dry summers. Notably, Southern Germany has been demonstrated to be a geographical center in terms of deficit volumes of precipitation and duration of drought (Laaha et al., 2017). Such changes in water availability affect plant growth, and can change patterns of competition and facilitation between plants (Walter, 2018).

Grasslands are important biomes rich in biodiversity, accounting for nearly 25\% of land surface on Earth (Gang et al., 2015); they offer key ecosystem services balancing the concentrations of global atmospheric greenhouse gases (O'Mara, 2012), protecting soil and water resources (Vogt et al., 2019) and providing livestock forage and therefore meat and milk for human consumption (O'Mara, 2012). Nevertheless, they are one of the most sensitive ecosystems to global climate change drivers (Seastedt and Pyšek, 2011), where anthropogenic influence accelerated their decline over the last decades (CzarnieckaWiera et al., 2019). Indeed, as a consequence of abandonment and changing of traditional management toward intensification, European grasslands have experienced a decrease in species richness and changes in competitive regimes (Römermann et al., 2009), being also increasingly disturbed by frequent mowing or grazing (Stampfli et al., 2018).

Climate change and extreme events influence the structure and function of ecosystems worldwide, jointly with plant invasion (Vitousek et al., 1997; Parmesan and Yohe, 2003; Kelly and Goulden, 2008). By altering the dominant perennial plant cover, increasing resource availability and opening space for colonization, disturbance facilitates the arrival and dispersal of invasive species (Pierce et al., 2013; Herben et al., 2018), which are often characterized by competitive functional traits such as larger size, increased fecundity and faster germination than native species (Callaway and Ridenour, 2004). Invasive plants benefit disproportionately from disturbance (Smith and Knapp, 1999) and, notably in grasslands, they can act as drivers of change (Vitousek et al., 1997), shifting ecosystems to alternative stable states that are less diverse and dominated by alien species (Gibbons et al., 2017). However, some studies highlighted that their performance may not differ from dominant native species (Sheppard et al., 2012).

The warty cabbage, Bunias orientalis L. (Brassicaceae), benefits from excessive disturbance, copes very well with mowing due to rapid rosette regrowth and increased seedling recruitment (Woitke and Dietz, 2002) and forms tall dense stands that successfully compete with native grasses for sunlight, nutrients, and pollinators (Birnbaum, 2006). Over the last four decades the species has become highly invasive in various parts of Northern and Central Europe, including German grasslands
(Dietz et al., 1996, 1999; Woitke and Dietz, 2002). In this region, grasslands account for more than a quarter of farmed land, with more than half of all plant species found in the country depending on the habitat. However, in recent decades they have been under pressure, with a decline by $12 \%$ from over 5.3 million hectares reported in 1991 to $4.7 \mathrm{~m}$ ha nowadays (Umweltbundesamt, 2020).

In this study, we focus on how invasion success of $B$. orientalis in native grassland communities in Germany may change with varying hydrological conditions (ranging from very dry to waterlogged by adjusting water table depth) that are expected under climate change. We conducted a 3-year mesocosm experiment in a common garden addressing the following research questions: (1) Does the establishment and growth of B. orientalis differ among water table depths? (2) Does the effect of water table depth depend on the presence and biomass of the native grassland community?

\section{MATERIALS AND METHODS}

\section{Study Species}

Bunias orientalis is a tall (up to $1.2 \mathrm{~m}$ height) polycarpic biennial or perennial hemicryptophyte of high dispersal ability that may live up to 10 years or even longer; it grows as a semi-rosette with large leaves and numerous little flowers. The species is hermaphroditic and insect-pollinated, with a self-fertile breeding system (Dietz et al., 1999), but it can also reproduce vegetatively by root fragments (Bąba and Kompała-Bąba, 2008). B. orientalis has a high reproductive effort (from 15 up to $45 \%$ of reproductive biomass i.e., g dry weight of reproductive biomass per $g$ aboveground biomass), high germination rates (up to $60 \%$ ) and a high potential for vegetative growth following root fragmentation (Steinlein et al., 1996). Moreover, it has a persistent seed bank, with large seeds (mean seed mass $7 \mathrm{mg}$, Dietz et al., 1999) occurring in densities from 1,000 to 15,000 seeds $/ \mathrm{m}^{2}$, able to be viable for more than 3 years (Steinlein et al., 1996).

The native range is Caucasus and southern Russia, where the species occurs in grasslands, sunny edges of forests, dappled shade and riverbanks. There, the species requires moist soils (Clapham et al., 1962). Multiple independent introductions in the 18th century brought $B$. orientalis to Europe where it rapidly became a dominant invasive species in many countries, including Germany, Czech Republic, Poland, Sweden, Norway, and elsewhere (Harvey et al., 2010). In other neighboring countries (France, Great Britain, Netherlands) the species is not yet considered invasive, although it occurs as an established neophyte. In the invaded range $B$. orientalis is highly versatile and easily establishes in a variety of semi-natural or disturbed habitats such as roadside verges, railways, fallow lands, floodplain meadows, pastures, ruderal sites, and even gardens (Birnbaum, 2006). In the invaded range the species is more tolerant to various soil conditions although it prefers open, nutrient rich clay or sand soils of a neutral $\mathrm{pH}$ and does not grow under shaded conditions. From these sites it can invade dry grasslands, especially neglected dry meadows (Birnbaum, 2006). Moderate disturbance caused by mechanical damage (e.g., mowing) or herbivore damage (e.g., 
slug grazing) promote the survival and establishment of the species (Bąba and Kompała-Bąba, 2008).

\section{Experimental Design}

To study the effects of hydrological stress on the establishment and growth of the invasive plant $B$. orientalis, we set up a mesocosm experiment in a common garden $\left(48^{\circ} 71^{\prime} \mathrm{N}, 9^{\circ} 20^{\prime}\right.$ E, $389 \mathrm{~m}$ a.s.l.) at the University of Hohenheim in Stuttgart, Germany. The climate is oceanic, subtype subcontinental, mild, with no dry season and warm summers. The long-term average annual temperature is $9.4^{\circ} \mathrm{C}$ and annual precipitation is $718 \mathrm{~mm}$ (Agrarmeteorologie Baden-Württemberg, 2019). The experiment was conducted from April 2016 to November 2018 and included five hydrological treatments (chronic drought, dry, mesic, wet, waterlogged), applied to bare soil (simulating disturbance) and grassland community pots.

Naturally composed mature grassland communities were dug out in November 2015 from four typical hay meadows (Arrhenatherion elatioris), which all belonged to the same organic farm property in South-Western Germany $\left(48^{\circ} 53^{\prime} \mathrm{N}, 8^{\circ} 54^{\prime} \mathrm{E}\right.$, 290-380 m a.s.l.). These dug-out communities (including soil, roots and the entire grassland community, with a soil depth of $15-20 \mathrm{~cm})$ were placed in $20-\mathrm{L}$ pots $(28 \mathrm{~cm} \times 35 \mathrm{~cm}$ ø), which were previously filled with a layer of sandy loam at the bottom. The communities thus had different species compositions (made up of mostly perennial grasses, forbs, and legumes), but provided a more natural environment to study invasion success. The communities contained on average 7.2 species at the start of the experiment in 2016, with the most common species being the grasses Arrhenatherum elatius (L.) P.Beauv. ex J. Presl \& C. Presl., Festuca pratensis Huds., and Poa pratensis L. (Supplementary Table S1). The bare soil pots were entirely filled with the same sandy loam used at the bottom of the grassland pots. All pots were then kept in the greenhouse until April 2016, when they were transferred to the common garden and placed inside large 260-L pools (Supplementary Figure S1). Each pot was placed in a separate pool to avoid pseudo-replication (with the exception of one pot of bare soil, which shared a pool with one community pot). The pools also contained some other pots, which however are not part of the experiment described here. Seeds of $B$. orientalis were sown on 30 June 2016 in 50 pots, of which 40 were with communities (8 replicates per water table depth treatment), and 10 control pots without (bare soil, 2 replicates per treatment). Within the logistical limitations of our experiment, we allocated more replicates for the community treatments as we expected lower establishment success in the grassland. In each pot, 12 seeds were sown, with a total number of 600 seeds.

We aimed to mimic a realistic scenario with natural variation in precipitation, applying different soil moisture conditions on these near-natural grassland communities, ranging from waterlogged, over wet, mesic, dry to chronic-drought-exposed communities. We achieved the desired hydrological regimes by adjusting the water table depth in the pools to five levels (Supplementary Figure S2). In the waterlogged treatment, the water table was kept at $-5 \mathrm{~cm}$ below the soil surface, in the wet treatment at $-15 \mathrm{~cm}$ and in the mesic treatment at
$-25 \mathrm{~cm}$. The water table depth was kept constant by watering the pools twice per week and preventing higher water levels than desired with holes in the pools made at the respective height (Supplementary Figure S2; see also Rai et al., 2018; Walter, 2020). In the dry treatment, pools contained no water (i.e., holes at the bottom) and pots received natural rainfall. Under chronic drought conditions, precipitation was additionally reduced by $30 \%$ with a partial rainout shelter, using curved, transparent PVC stripes mounted on a wooden construction that covered $30 \%$ of the area above the pools (Supplementary Figures S1, S2).

The year 2016 was characterized by an exceptionally wet June (115 mm rainfall compared to the long-term 30-year average (1981-2010), mean of $87 \mathrm{~mm}$ ), followed by an exceptionally dry period from July to September (only $117 \mathrm{~mm}$ rainfall compared to $212 \mathrm{~mm}$ in the long-term mean) (Agrarmeteorologie BadenWürttemberg, 2019). 2017 received almost $130 \mathrm{~mm}$ more rainfall than the long-term during the growing season (from April until November), with June and July being especially moist months (+ $67 \mathrm{~mm}) .2018$ had a record-breaking dry and hot summer $\left(+2.1^{\circ}\right.$ and $120 \mathrm{~mm}$ less precipitation than the long-term average, from April until November) (Agrarmeteorologie BadenWürttemberg, 2019). As expected, soil moisture differed among the applied hydrological treatments (see Walter, 2020 for details on average volumetric soil water content).

During the first year, germination of $B$. orientalis seedlings was monitored at weekly intervals until the end of October. In each year, number of $B$. orientalis individuals were counted in late May or beginning of June and at the end of October, after which all plant material (B. orientalis and the community) was cut $2 \mathrm{~cm}$ aboveground (mimicking extensive agricultural regimes). In each October, aboveground biomass of $B$. orientalis and the grassland communities were harvested, dried at $60^{\circ}$ for 4 days and weighed.

\section{Data Analysis}

Statistical analyses were performed with R 3.6.1 (R Core Team, 2019) using the lme4 R package (Bates et al., 2015). For those seeds that germinated during the first season (2016), we used a linear mixed effects model to test whether time of germination (i.e., week after sowing, up to week 14 referring to the week of harvest) was affected by water table depth (factor with 5 levels: chronic drought, dry, mesic, wet, waterlogged) and the presence of the community (2 levels: community, bare soil) and their interaction. Pot identity (factor with 50 levels) was included as a random effect. Marginal and conditional $R^{2}$ was calculated using the MuMIn package (Barton, 2020).

For the analysis of number of individuals per pot over the 3 years, a generalized linear mixed model was employed with a Poisson distribution. The temporal (pseudo-)replicates of dataassessments were used as a random effect (5 levels: October 2016, May 2017, October 2017, June 2018, October 2018) as well as pot identity to account for repeated measures on the same pot. For (log-transformed) aboveground biomass, a linear mixed effects model was applied, using timing of harvest as a random effect (3 levels: October 2016, October 2017, October 2018). Note that in these models, due to singular fit issues, we were not able to account for pot identity. Water table depth and community as well as their interaction were used as fixed effects. 
In a first step, we tested whether the interaction between water table depth and presence of the community was significant (tested using likelihood ratio tests with a chi-squared test statistic). If the interaction was significant, separate models for each community type were employed in a second step. For the pots with the community, we then additionally tested whether community biomass affected $B$. orientalis performance, adding this as a fixed effect to the above-mentioned models.

\section{RESULTS}

\section{Effect of Water Table Depth and Community on Germination of Bunias orientalis}

The percentage of germinated seeds of Bunias orientalis in 2016 was higher in bare soil (53\% i.e., 64/120) compared to community pots (15\% i.e., 72/480). The effect of water table depth on germination time was not significantly affected by the presence of the native grassland community (i.e., no significant interaction, Table 1).

However, seeds in bare soil pots germinated 3 weeks (on average) earlier than seeds in the community (Table 1 and Figure 1). Time of germination was significantly affected by water table depth (Table 1), with an earlier germination in the wet treatment (mean germination time $5.95 \pm 0.51$ week after sowing, Figure 1) followed by the mesic and waterlogged treatments (mean $6.98 \pm 0.52$ and $7.20 \pm 1.74$ week, respectively). Notably, seeds in the dry (mean $8.18 \pm 1.01$ week) and chronic drought treatments (mean $8.78 \pm 1.12$ week) germinated on average $2-3$ weeks later than seeds in the other treatments, irrespective of whether they were growing in bare soil pots or communities.

\section{Effect of Water Table Depth and Community on Number of Established Individuals}

The number of established individuals decreased over time: 136 seeds had germinated by October 2016, whereas 73 individuals (51 in bare soil, 22 within the community) were recorded in October 2017 and only 8 individuals (7 in bare soil pot, 1 within community) survived until October 2018 by the end of the experiment (Supplementary Figure S3).

The effect of water table depth on the number of individuals did not depend on whether plants were growing in the community (Table 1, Figure 2, and Supplementary Figure S3). Indeed, both in the community and in bare soil pots, the number of individuals significantly differed among water table depth (Table 1 and Figure 2). Most individuals established in mesic conditions and bare soil pots (mean $5.8 \pm 1.6$ ).

In communities, the number of individuals was also affected by community biomass $\left[\chi^{2}(1 \mathrm{df})=6.53 ; p=0.011\right]$, which ranged between 0.29 and $130.48 \mathrm{~g}$, with an average of $35.69 \mathrm{~g} /$ pot. The highest number of individuals that established per pot were observed in native grassland communities where community biomass was lower than the average (i.e., 10, 8, and 7 individuals/pot established respectively in community biomass of $17.57,28$, and $17.73 \mathrm{~g}$ ), with a general trend of individuals having successfully established in communities with a biomass lower than $80 \mathrm{~g}$ (Supplementary Figure S4).

\section{Effect of Water Table Depth and Community on Plant Biomass}

The effect of water table depth on aboveground plant biomass significantly depended on whether plants were growing in the community (Table 1, Figure 3, and Supplementary Figure S5). Both in the community and in bare soil pots plant biomass differed among water table depth (Table 1 and Figure 3). In communities, the species reported a significantly higher biomass in mesic (mean $0.051 \pm 0.021 \mathrm{~g}$ ) and wet conditions $(0.047 \pm 0.018 \mathrm{~g})$, however community biomass did not affect $B$. orientalis biomass $\left[\chi^{2}(1 \mathrm{df})=0.031 ; p=0.86\right]$. Conversely, biomass of $B$. orientalis observed in bare soil was the highest in pots that received only natural rainfall, i.e., the dry treatment $(1.571 \pm 0.783 \mathrm{~g}$, Figure 3$)$, followed by the mesic treatment (mean $1.153 \pm 0.737 \mathrm{~g}$ ). We noted that B. orientalis never flowered during the experiment.

\section{DISCUSSION}

\section{Establishment and Growth of Bunias orientalis in Bare Soil and Native Grassland Communities}

In contrast to its previously demonstrated invasiveness (Steinlein et al., 1996; Dietz and Steinlein, 1998; Dietz et al., 1999; Woitke and Dietz, 2002; Birnbaum, 2006), the overall performance of Bunias orientalis in our experiment was rather low, with less than $23 \%$ of seeds having established after the first season and just 8 individuals surviving at the end of the experiment. Previous studies already reported a low germination rate (20\%) in ruderal sites characterized by low intensity of disturbance (mowing) and soil deposition, whereas germination reached the highest rates (60.1\%) in nitrogen rich, shady and moist soil (Steinlein et al., 1996). Probably competition by shading was too high in the still intact communities in 2016 (height of communities ranged between ca. $10-30 \mathrm{~cm}$ and cover between 80 and $100 \%$ ) to allow for high germination rates. Moreover, the exceptionally dry period in mid-summer 2016 and the record-breaking dry and hot summer of 2018 could have impacted negatively on seed germination and early seedling establishment, a phase demonstrated to be the most critical for water stress and plant survival (Ahmad et al., 2009).

The low performance of $B$. orientalis was also reflected in the finding that plants never flowered during the experiment, although the species normally flowers in the second year or later (Bąba and Kompała-Bąba, 2008). However, plants that can grow either biennially or perennially may use different strategies depending on the conditions they grow in: the reduced performance of plants may have allowed for a retention of accumulated resources for perennation (Miao and Bazzaz, 1990) and therefore selectively favored perennial plants (Steinlein et al., 1993). 
TABLE 1 | Linear mixed effect models for germination time of Bunias orientalis in the first season (2016) and biomass over 3 years (2016-2018), and generalized linear mixed model for number of individuals over 3 years.

\begin{tabular}{|c|c|c|c|}
\hline & Germination time & No. individuals & Biomass \\
\hline Water table depth $\times$ Treatment & $\begin{array}{l}x^{2}(4 \mathrm{df})=3.99 \\
p=0.407\end{array}$ & $\begin{array}{l}x^{2}(4 \mathrm{df})=5.09 \\
p=0.278\end{array}$ & $\chi^{2}(4 \mathrm{df})=17.13 ; p=0.002$ \\
\hline Water table depth & $\begin{array}{l}\chi^{2}(4 \mathrm{df})=12.87 \\
\quad p=0.012\end{array}$ & $\begin{array}{l}\chi^{2}(4 \mathrm{df})=34.87 \\
\quad p<0.001\end{array}$ & $\begin{array}{l}\text { Community: } \chi^{2}(4 \mathrm{df})=18.79 ; p<0.001 \\
\text { Bare soil: } \chi^{2}(4 \mathrm{df})=8.84 ; p=0.060\end{array}$ \\
\hline Treatment & $\begin{array}{l}\chi^{2}(1 \mathrm{df})=18.11 \\
\quad p<0.001\end{array}$ & $\begin{array}{l}\chi^{2}(1 \mathrm{df})=31.20 \\
\quad p<0.001\end{array}$ & \\
\hline$R^{2}$ in\% (marginal/conditional) & $21.0(33.6)$ & $34.7(79.3)$ & $\begin{array}{l}\text { Full model: } 24.9 \text { (60.7); Community model: } 8.2 \\
\text { (50.7); Bare soil model: } 12.0(61.0)\end{array}$ \\
\hline
\end{tabular}

Results from likelihood ratio tests for the effects of water table depth, treatment and their interaction are shown. (Marginally) significant values ( $\mathrm{p}<0.1)$ are indicated in

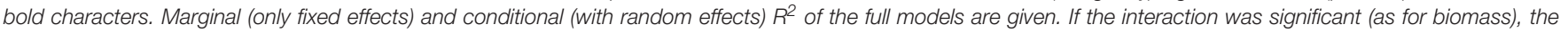
effect of water table depth was tested in separate models for community and bare soil.

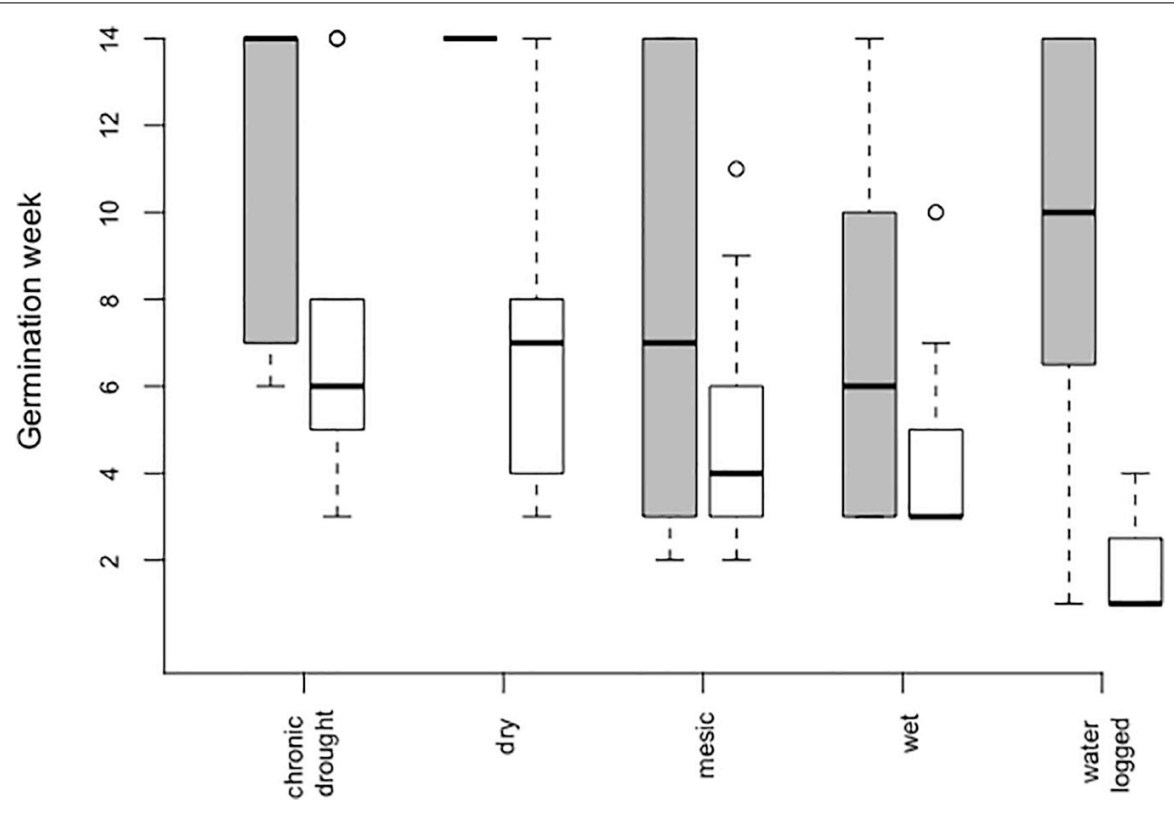

FIGURE 1 | Germination time in weeks after sowing of Bunias orientalis during the first season (2016) depending on water table depth treatment in the community (gray bars, $n=5,3,45,34$, and 7 individuals) and empty pots (white bars, $n=9,14,23$, 22, and 3 individuals). Boxplots show the median per group (solid line), boxes represent the 25 th and 75 th quantile, whiskers the normal data range and circles the outliers.

In addition to the overall low performance, $B$. orientalis performance was clearly constrained by interspecific competition with the native grassland community. Other studies also showed higher growth of $B$. orientalis in the absence of competition, such as higher biomass (Koorem et al., 2018), higher cumulative leaf lengths of the species and higher seed numbers (Dietz et al., 1999). Reducing total cover of all other species, Kiełtyk (2014) demonstrated that $B$. orientalis cover in meadows increases as a consequence. Given that we used natural dug-out mature communities, competition was high because communities were already well established. Light competition from taller species might be a limiting factor in the establishment of the species (Dietz et al., 1996). Indeed, community biomass affected how many individuals established over the years, but notably it did not with regard to $B$. orientalis biomass, whereby either fewer individuals formed the classic large rosettes occupying the given area or more individuals remained smaller. To compensate for its low competitive ability compared with other ruderal forbs (Dietz et al., 1998; Birnbaum, 2006), B. orientalis has been shown to use other strategies to successfully invade: it requires moderate disturbance to establish, that facilitates invasion by reducing competition and changing resource conditions in favor of one species over another (Hager, 2004; Domènech and Vilà, 2008). For instance, formation of molehills which damages resident vegetation and creates open areas of bare soil, leading to less-compacted soil and vegetation with a lower-density rhizosphere, facilitates invasion of $B$. orientalis (Kiełtyk and Mirek, 2015). In contrast, mimicking standard management practices in extensively used semi-natural grasslands in our study, with mowing twice a year, did not favor the establishment, survival and potential invasiveness of the plants, maybe because the degree of disturbance was too low. However, simulating 


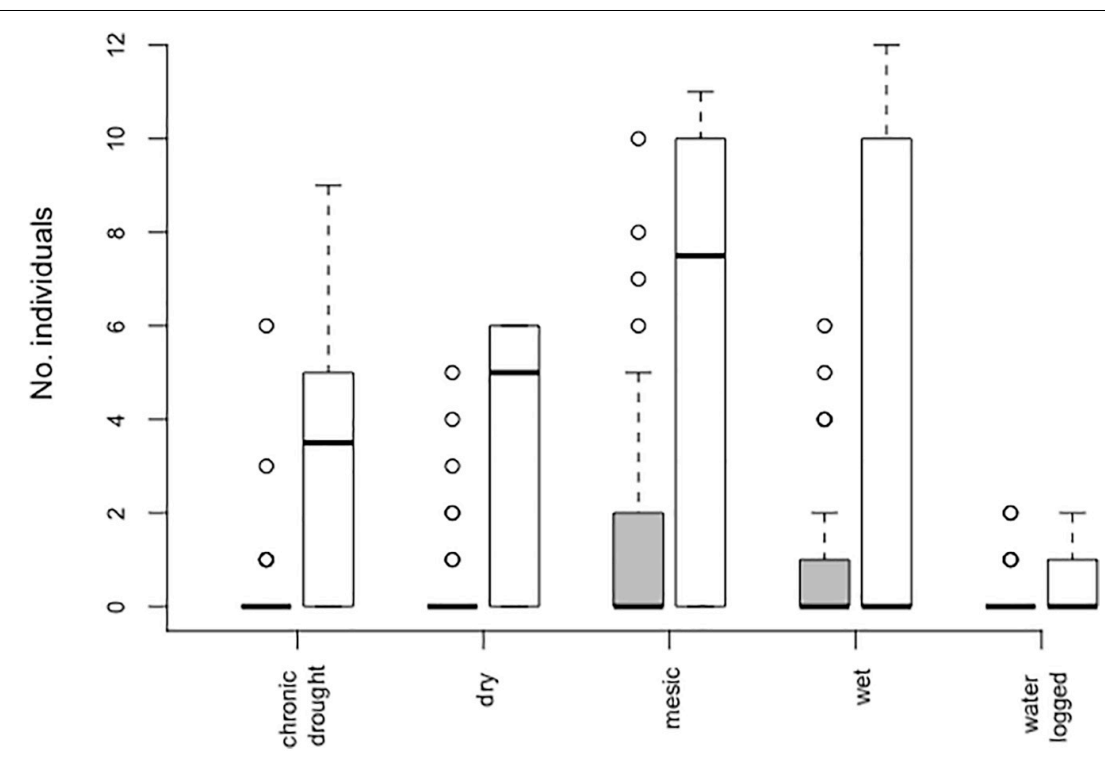

FIGURE 2 | Number of Bunias orientalis individuals established per pot (from initially 12 sown seeds) over 3 years (2016-2018) depending on water table depth treatment in the community (gray bars, $n=40$ each) and empty pots (white bars, $n=10$ each). Boxplots show the median per group (solid line), boxes represent the 25th and 75th quantile, whiskers the normal data range and circles the outliers.

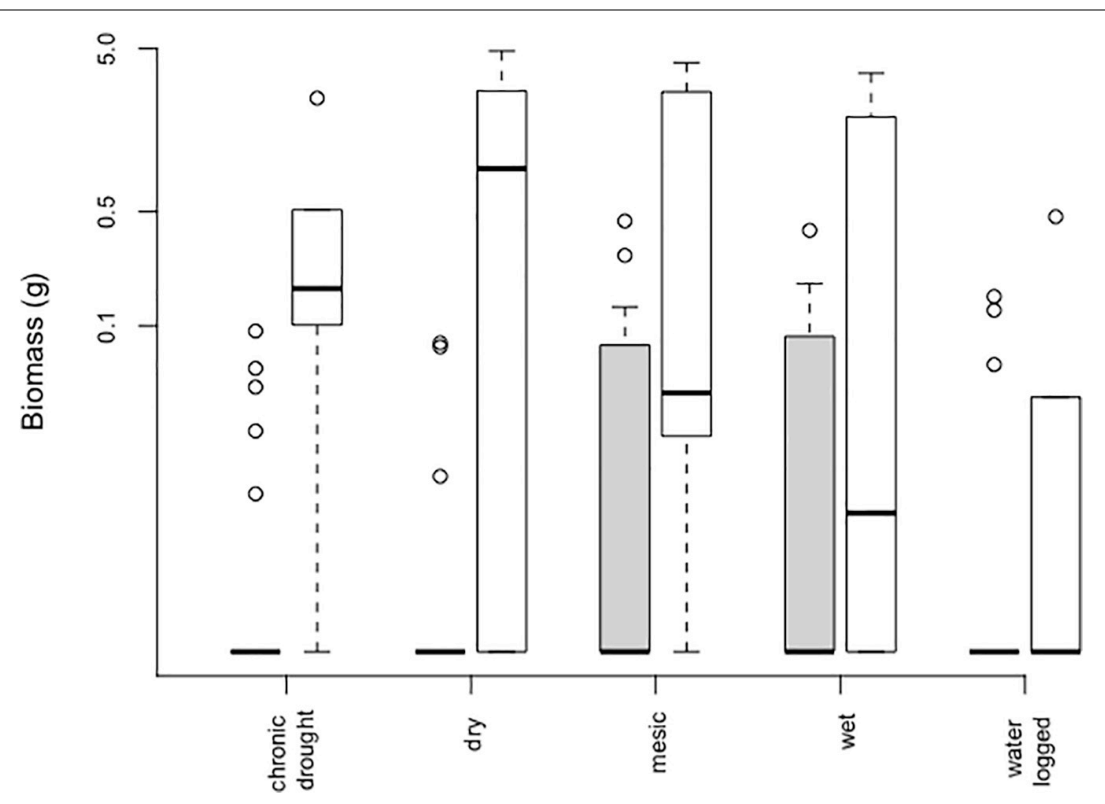

FIGURE 3 | Aboveground biomass of Bunias orientalis over 3 years (2016-2018) depending on water table depth treatment in the community (gray bars, $n=24$ each) and empty pot (white bars, $n=6$ each). Boxplots show the median per group (solid line), boxes represent the 25 th and 75 th quantile, whiskers the normal data range and circles the outliers. The y-axis is shown on a log-scale.

a high degree of disturbance with the bare soil pots greatly increased performance of $B$. orientalis.

\section{Effect of Hydrological Stress on Bunias orientalis Performance}

The different soil moisture conditions that we created by adjusting water table depth, simulating wetness, temporary flooding and especially dryness strongly influenced the performance of the plants. Seed germination in the first season occurred earlier and the number of established individuals as well as biomass production over the following years was generally higher in the wet and mesic treatments. Indeed, even though $B$. orientalis exhibits a wide ecological tolerance, previous studies showed that the species establishes better in moist soils (Clapham et al., 1962; Steinlein et al., 1996). 
Notably, B. orientalis showed greater performance and a wider ecological tolerance along the hydrological gradient in bare soil than in the community, with competition with the surrounding vegetation influencing the establishment and growth of the species. In particular, while establishment was highest in mesic and wet conditions regardless of the community, the presence of the community mostly limited plant growth to mesic and wet conditions. In contrast, plant biomass production in bare soil was not restricted to the non-stressful hydrological conditions, with the highest biomass found in dry condition, but moderate performance also observed in wetter treatments. This finding suggests that the smaller number of individuals on average established in dry treatments compensated for their number by producing more biomass. We note some limitation with the interpretation of the biomass results, however, because due to the limited number of pots in our experiment, we could not fully statistically account for non-independence among repeated measurements. Nevertheless, there are some likely explanations for our results. Reduced intraspecific competition might have favored faster growth rates in the dry treatments. In contrast, despite the lower aboveground biomass in dry communities, belowground competition for water might have become more severe, as found in other experimental studies (e.g., Walter, 2018). This may have limited plant growth of B. orientalis seedlings in interspecific competition under such resource stress, especially since seedlings usually have a smaller root system than established plants. The generally lower success of plants in waterlogged conditions (whereby differences between bare soil pots and community were less pronounced) may be attributed to anaerobic stress rather than increased competition, because special adaptations are necessary to cope with anoxia, as has been shown in other studies (Jung et al., 2009; Bartelheimer and Poschlod, 2016).

The results of our study have implications regarding possible changes in the dynamics between native and the invasive species in the future, based on the timing and frequency of precipitation patterns: the establishment of $B$. orientalis seedlings might turn into a successful invasion only if germination of seeds will occur in moderate precipitation conditions, followed by drought conditions coupled with disturbance. Therefore, rainy and wet springs and warmer summers might help the invasion success of this species, particularly if a disturbance creates patches of bare soil.

\section{CONCLUSION}

We conducted a 3-year mesocosm experiment in a common garden focusing on the invasion success of the warty cabbage

\section{REFERENCES}

Agrarmeteorologie Baden-Württemberg (2019). Available online at: https://www. wetter-bw.de/ (accessed March, 2020).

Ahmad, S., Ahmad, R., Ashraf, M. Y., Ashraf, M., and Waraich, E. A. (2009). Sunflower (Helianthus annuus L.) response to drought stress at germination and seedling growth stages. Pak. J. Bot. 9, 647-654.
Bunias orientalis in German native grassland communities. Thereby we compared the establishment and growth of plants in such communities with bare soil in varying hydrological conditions (from waterlogged to dry soil moisture), mimicking predicted changes in precipitation patterns under climate change. Establishment and biomass of $B$. orientalis differed among water table depth, with higher performance in wet and mesic conditions. However, despite its wide ecological tolerance in the absence of competing plants, invasion success of $B$. orientalis in the native grassland communities was generally low, which might be due to the low competitive ability of the species in conditions of hydrological stress and the fairly low degree of disturbance in our near-natural grasslands. Our results suggest that with changing of precipitation patterns toward more extreme events with frequent and pronounced waterlogged and drought conditions, the establishment of $B$. orientalis within grassland communities might be reduced. However, within patches of bare soil, this will not occur, where disturbance combined with drought will favor species establishment, survival and even invasiveness, a scenario which should be further tested in future studies.

\section{DATA AVAILABILITY STATEMENT}

The raw data supporting the conclusions of this article will be made available by the authors, without undue reservation.

\section{AUTHOR CONTRIBUTIONS}

JW and CS designed the study. AC and JW collected the data. $\mathrm{AC}$ and CS performed the analyses. AC wrote the first draft of the manuscript. All authors contributed substantially to the revisions.

\section{FUNDING}

This work was supported by the German Research Foundation (DFG, WA 3442/2-1 and SH 924/1-1).

\section{SUPPLEMENTARY MATERIAL}

The Supplementary Material for this article can be found online at: https://www.frontiersin.org/articles/10.3389/fevo.2021. 625587/full\#supplementary-material

Bąba, W. J., and Kompała-Bąba, A. N. (2008). “Communities with Bunias orientalis in human-made habitats of the Silesian Upland (southern Poland)," in Plant Invasions: Human Perception, Ecological Impacts and Management, eds B. Tokarska-Guzik, J. H. Brock, G. Brundu, L. Child, C. C. Daehler, and P. Pyšek (Leiden: Backhuys Publishers), 189-206.

Bartelheimer, M., and Poschlod, P. (2016). Ellenberg's water table experiment put to the test: species optima along a hydrological 
gradient. Oecologia 181, 1163-1172. doi: 10.1007/s00442-0163624-3

Barton, K. (2020). MuMIn: Multi-Model Inference. R Package Version 1.43.17. Available online at: https://CRAN.R-project.org/package=MuMIn (accessed February, 2021).

Bates, D., Mächler, M., Bolker, B., and Walker, S. (2015). Fitting linear mixed-effects models using lme4. J. Stat. Softw. 67, 1-48.

Birnbaum, C. (2006). NOBANIS - Invasive Alien Species Fact Sheet - Bunias orientalis. Data from: Online Database of the European Network on Invasive Alien Species - NOBANIS. Availble online at: www.nobanis.org (accessed July $16,2020)$.

Callaway, R. M., and Ridenour, W. M. (2004). Novel weapons: invasive success and the evolution of increased competitive ability. Front. Ecol. Environ. 2:436-443. doi: 10.1890/1540-92952004002 [0436:NWISAT]2.0.CO;2

Clapham, A. R., Tutin, T. G., and Warburg, E. F. (1962). Flora of the British Isles. Cambridge: Cambridge University Press.

Czarniecka-Wiera, M., Kącki, Z., Chytrý, M., and Palpurina, S. (2019). Diversity loss in grasslands due to the increasing dominance of alien and native competitive herbs. Biodivers. Conserv. 28, 2781-2796. doi: 10.1007/s10531019-01794-9

Dietz, H., and Steinlein, T. (1998). "The impact of anthropogenic disturbance on life stage transitions and stand regeneration of the invasive alien plant Bunias orientalis L," in Plant Invasions - Ecological Mechanisms and Human Responses, eds U. Starfinger, K. Edwards, I. Kowarik, and M. Williamson (Leiden: Backhuys Publishers), 169-184.

Dietz, H., Steinlein, T., and Ullmann, I. (1998). The role of growth form and correlated traits in competitive ranking of six perennial ruderal plant species grown in unbalanced mixtures. Acta Oecol. 19, 25-36. doi: 10.1016/s1146609x(98)80005-2

Dietz, H., Steinlein, T., and Ullmann, I. (1999). Establishment of the invasive perennial herb Bunias orientalis L.: an experimental approach. Acta Oecol. 20, 621-632. doi: 10.1016/s1146-609x(99)00104-6

Dietz, H., Steinlein, T., Winterhalter, P., and Ullmann, I. (1996). Role of allelopathy as a possible factor associated with the rising dominance of Bunias orientalis $\mathrm{L}$. (Brassicaceae) in some native plant assemblages. J. Chem. Ecol. 22, 1797-1811. doi: $10.1007 / \mathrm{bf} 02028505$

Domènech, R., and Vilà, M. (2008). Response of the invader Cortaderia selloana and two coexisting natives to competition and water stress. Biol. Invasions 10 , 903-912. doi: 10.1007/s10530-008-9243-0

Gang, C., Zhou, W., Wang, Z., Chen, Y., Li, J., Chen, J., et al. (2015). Comparative assessment of grassland NPP dynamics in response to xlimate xhange in China, North America, Europe and Australia from 1981 to 2010. J. Agro. Crop Sci. 201, 57-68. doi: 10.1111/jac. 12088

Gibbons, S. M., Lekberg, Y., Mummey, D. L., Sangwan, N., Ramsey, P. W., and Gilbert, J. A. (2017). Invasive plants rapidly reshape soil properties in a grassland ecosystem. mSystems 2:e00178-16.

Hager, H. (2004). Competitive effect versus competitive response of invasive and native wetland plant species. Oecologia 139, 140-149. doi: 10.1007/s00442-0041494-6

Hanel, M., Rakovec, O., Markonis, Y., Maica, P., Samaniego, L., Kyselyì, J., et al. (2018). Revisiting the recent European droughts from a long-term perspective. Nature 8:9499. doi: 10.1038/s41598-018-27464-4

Harvey, J. A., Biere, A., Fortuna, T., Vet, L. E. M., Engelkes, T., Morriën, E., et al. (2010). Ecological fits, mis-fits and lotteries involving insect herbivores on the invasive plant, Bunias orientalis. Biol. Invasions 12, 3045-3059. doi: 10.1007/s10530-010-9696-9

Herben, T., Klimešová, J., and Chytrý, M. (2018). Effects of disturbance frequency and severity on plant traits: an assessment across a temperate flora. Funct. Ecol. 32, 799-808. doi: 10.1111/1365-2435.13011

IPCC (2014). Climate Change 2014: Synthesis Report. Contribution of Working Groups I, II and III to the Fifth Assessment Report of the Intergovernmental Panel on Climate Change, eds Core Writing Team, R. K. Pachauri, and L. A. Meyer (Geneva: IPCC).

Jung, V. B., Mony, C., Hoffmann, L., and Muller, S. (2009). Impact of competition on plant performances along a flooding gradient: a multispecies experiment. J. Veg. Sci. 20, 433-441. doi: 10.1111/j.1654-1103.2009. 05786.x
Kelly, A. E., and Goulden, M. L. (2008). Rapid shifts in plant distribution with recent climate change. Proc. Natl. Acad. Sci. U.S.A. 105, 11823-11826. doi: $10.1073 /$ pnas. 0802891105

Kiełtyk, P. (2014). Distribution pattern of the invasive alien plant Bunias orientalis in Rów Podtatrzański trench, north of the Tatra Mts, Poland. Biologia 69, 323-331.

Kiełtyk, P., and Mirek, Z. (2015). Importance of molehill disturbances for invasion by Bunias orientalis in meadows and pastures. Acta Oecol. 64, 29-34. doi: 10.1016/j.actao.2015.02.007

Koorem, K., Kostenko, O., Snoek, L. B., Weser, C., Raminez, K. S., Wilschut, R. A., et al. (2018). Relatedness with plant species in native community influences ecological consequences of range expansions. Oikos 127, 981-990. doi: 10.1111/ oik.04817

Laaha, G., Gauster, T., Tallaksen, L. M., Vidal, J.-P., Stahl, K., Prudhomme, C., et al. (2017). The European 2015 drought from a hydrological perspective. Hydrol. Earth Syst. Sci. 21, 3001-3024.

Miao, S. L., and Bazzaz, F. A. (1990). Responses to nutrient pulses of two colonizers requiring different disturbance frequencies. Ecology 71, 2166-2178. doi: 10. 2307/1938630

O'Mara, F. P. (2012). The role of grasslands in food security and climate change. Ann. Bot. 110, 1263-1270. doi: 10.1093/aob/mcs209

Orlowsky, B., and Seneviratne, S. I. (2013). Elusive drought: uncertainty in observed trends and short- and long-term CMIP5 projections. Hydrol. Earth Syst. Sci. 17, 1765-1781. doi: 10.5194/hess-17-1765-2013

Parmesan, C., and Yohe, G. (2003). A globally coherent finger-print of climate change impacts across natural systems. Nature 421, 37-42. doi: 10.1038/ nature 01286

Pierce, S., Brusa, G., Vagge, I., and Cerabolini, B. E. L. (2013). Allocating CSR plant functional types: the use of leaf economics and size traits to classify woody and herbaceous vascular plants. Funct. Ecol. 27, 1002-1010. doi: 10.1111/13652435.12095

R Core Team (2019). R: A Language and Environment for Statistical Computing. Vienna, Austria: R Foundation for Statistical Computing. Available online at: https://www.R-project.org/

Rai, B., Klein, A. M., and Walter, J. (2018). Chronic dryness and wetness and especially pulsed drought threaten a generalist arthropod herbivore. Oecologia 188, 931-943. doi: 10.1007/s00442-018-4255-7

Römermann, C., Bernhardt-Römermann, M., Kleyer, M., and Poschlod, P. (2009). Substitutes for grazing in semi-natural grasslands - do mowing or mulching represent valuable alternatives to maintain vegetation structure? J. Veg. Sci. 20, 1086-1098. doi: 10.1111/j.1654-1103.2009.01106.x

Seastedt, T. R., and Pyšek, P. (2011). Mechanisms of plant invasions of North American and European grasslands. Annu. Rev. Ecol. Evol. Syst. 42, 133-153. doi: 10.1146/annurev-ecolsys- 102710- 145057

Sheppard, C. S., Alexander, J. M., and Billeter, R. (2012). The invasion of plant communities following extreme weather events under ambient and elevated temperature. Plant Ecol. 213, 1289-1301. doi: 10.1007/s11258-012-0086-5

Smith, M. D., and Knapp, A. K. (1999). Exotic plant species in a C4- dominated grassland: invasibility, disturbance, and community structure. Oecologia 120 , 605-612. doi: 10.1007/s004420050896

Stampfli, S., Bloor, J. M. G., Fischer, M., and Zeiter, M. (2018). High land-use intensity exacerbates shifts in grassland vegetation composition after severe experimental. Glob. Chang. Biol. 24, 2021-2034. doi: 10.1111/gcb.14046

Steinlein, T., Dietz, H., and Ullmann, I. (1996). Growth patterns of Bunias orientalis (Brassicaceae) underlying single dominance in some native plant assemblages. Vegetatio 125, 73-82. doi: 10.1007/bf00045206

Steinlein, T., Heilmeier, H., and Schulze, E. D. (1993). Nitrogen and carbohydrate storage in biennials originating from habitats of different resource availability. Oecologia 93, 374-382. doi: $10.1007 / \mathrm{bf} 00317881$

Umweltbundesamt (2020). Available online at: https://www.umweltbundesamt.de/ (accessed March, 2020).

Vitousek, P. M., Mooney, H. A., Lubchenco, J., and Melillo, J. (1997). Human domination of Earth's ecosystems. Science 277:5325. doi: 10.1007/978-0-38773412-5_1

Vogt, J., Klaus, V. H., Both, S., Fürstenau, C., Gockel, S., Gossner, M. M., et al. (2019). Eleven years' data of grassland management in Germany. Biodivers. Data J. 7:e36387. doi: 10.17616/R32P9Q 
Walter, J. (2018). Effects of changes in soil moisture and precipitation patterns on plant-mediated biotic interactions in terrestrial ecosystems. Plant Ecol. 219, 1449-1462. doi: 10.1007/s11258-018-0893-4

Walter, J. (2020). Dryness, wetness and temporary flooding reduce floral resources of plant communities with adverse consequences for pollinator attraction. J. Ecol. 108, 1453-1464. doi: 10.1111/1365-2745. 13364

Woitke, M., and Dietz, H. (2002). Shifts in dominance of native and invasive plants in experimental patches of vegetation. Perspect. Plant Ecol. 5, 165-184. doi: 10.1078/1433-8319-00032
Conflict of Interest: The authors declare that the research was conducted in the absence of any commercial or financial relationships that could be construed as a potential conflict of interest.

Copyright (c) 2021 Corli, Walter and Sheppard. This is an open-access article distributed under the terms of the Creative Commons Attribution License (CC BY). The use, distribution or reproduction in other forums is permitted, provided the original author(s) and the copyright owner(s) are credited and that the original publication in this journal is cited, in accordance with accepted academic practice. No use, distribution or reproduction is permitted which does not comply with these terms. 